\title{
Erratum to: Results of a Feeding Protocol in Patients Undergoing the Hybrid Procedure
}

Kirby-Rose Carpenito ${ }^{1} \cdot$ Regina Prusinski $^{1} \cdot$ Kristin Kirchner $^{1} \cdot$ Janet Simsic $^{1}$. Yongjie Miao $^{1} \cdot$ Wendy Luce $^{1} \cdot$ John P. Cheatham ${ }^{1} \cdot$ Mark Galantowicz $^{1}$.

Carl H. Backes ${ }^{1} \cdot$ Clifford L. Cua ${ }^{1}$

Published online: 21 April 2016

(C) Springer Science+Business Media New York 2016

\section{Erratum to: Pediatr Cardiol}

\section{DOI 10.1007/s00246-016-1359-x}

The original version of this article unfortunately contained a mistake in the author's group. The middle name of the co-author was incorrectly displayed as $\mathrm{H}$ Backes $\mathrm{C}$ instead of Backes $\mathrm{CH}$. This has been corrected in the original version of the article.

The online version of the original article can be found under doi: 10.1007/s00246-016-1359-x.

Clifford L. Cua

clcua@hotmail.com

1 Heart Center, Nationwide Children's Hospital, Columbus, $\mathrm{OH} 43205$, USA 